\title{
Research on the Impact of the COVID-19 on the Consumer Goods Industry Group in the U.S. Stock Market
}

\author{
Rui Wang, * \\ ${ }^{1}$ School of Accounting, Southwestern University of Finance and Economics, Sichuan 611130, China \\ *Corresponding author. Email:41914376@smail.swufe.edu.cn
}

\begin{abstract}
The COVID-19 epidemic has severely affected the world economy, and the consumer goods industry in the United States has been influenced. Based on the Fama-French five-factor model, this study uses data from Ken.French/Data_Library website to perform multiple linear regression analysis. The research results show that the consumer goods industry group's overall market risk (Mkt-Rf) has increased slightly. The RMW of the food and soda industries after the epidemic has become significant and is negatively correlated with the rate of return $\mathrm{R}_{\mathrm{i}}$. The $\mathrm{SMB}$ of the beer industry has become significant after the epidemic and is related to the rate of return is positive. The smoke industry has become significant in HML, RMW, and CMA after the epidemic. The epidemic's impact on the consumer goods industry is not very serious, and the entire industry fluctuates slightly.
\end{abstract}

Keywords: Fama-French five-factor Model, COVID-19, Consumer goods industry, U.S. stock market.

\section{INTRODUCTION}

\subsection{Background}

Beginning in February 2020, the COVID-19 epidemic has broken out on a large scale globally, which has had a very serious impact on most industrial economies. Among them, U.S. stocks fuse several times, and oil prices once fell to negative numbers. Most people choose homestays, which impacts the demand for some consumer goods such as food, beer, and cigarettes. The situation of home isolation has caused the demand of the above consumer goods industries to show an increasing trend. To further explore the profitability of the consumer goods industry, the study selected data before and after the epidemic for comparative analysis.

The Capital Asset Pricing Model (CAPM) proposed by Jack Treynor, William F. Sharpe, John Lintner, and Jan Mossin is an important model for studying the rate of return on capital [1]. However, because CAPM believes that stock returns only have a linear relationship with the systemic risk of the entire stock market $\left[\mathrm{R}_{\mathrm{it}}-\mathrm{R}_{\mathrm{ft}}=\beta_{i}\left(\mathrm{R}_{\mathrm{mt}}-\mathrm{R}_{\mathrm{ft}}\right)\right]$, it has limitations. Therefore, the research uses the Fama-French model as an optimized solution since it enhances efficiency in studying the capital market. Eugene F. Fama and Kenneth R. French proposed the Fama-French threefactor model(FF3F) in 1993 [1] and later developed it into the Fama-French five-factor model in 2015(FF5F) [2]. This model considers five factors (Mkt-RF, SMB, HML, RMW \& CMA) contributing to the rate of return on capital. Considering that the Fama-French five-factor model has a broader effect today's capital market, the research uses the FF5F to study stock market data.

\subsection{Related Research}

The Fama-French five-factor model (FF5F) is developed based on the Fama-French three-factor model (FF3F), which is based on and developed from the CAPM model. Fama and French made international tests of the five-factor model. Their research shows that the five-factor model that adds profitability and investment factors to the three-factor model of Fama and French [2] has largely absorbed the average return model. Furthermore, the results of the model are also diverse in different parts of the world. The study illustrates that average stock returns in North America, Europe, and the Asia Pacific increase with book-tomarket value $(\mathrm{B} / \mathrm{M})$ and profitability and negatively correlate with investment. The relationship between average return and $\mathrm{B} / \mathrm{M}$ is strong for Japan, but the 
average return has little to do with profitability or investment [2]. Some scholars have confirmed the high applicability of FF5F through research on some industries. Madanoglu et al. study the advantages of the Fama-French model over the CAPM model through the evidence from the lodging industry. This study empirically studies two main equity model components to explain the variability of returns on accommodation stocks. The results show that the Fama-French model is consistently better than the capital property pricing model in the explanatory power of the cross-sectional accommodation industry portfolio returns during the 1993-2002 and 1998-2002 test periods. Furthermore, the Fama-French model provides a more realistic estimate of the cost of equity by adjusting the size of the accommodation portfolio and financial difficulties [3]. Gonçalves and Carvalhal investigate whether FamaFrench's scale and value factors (SMB and HML) can predict past returns. Their analysis controlled different macroeconomic variables and company characteristics, such as corporate governance practices, scale, dividend yield, book-to-market ratio, etc. Analysis shows that 14 out of 16 industries forecast SMB one month ahead of schedule. In addition, the returns of some industries can predict the volatility of SMB and HML three months in advance. The statistics show that the predictability for HML is weaker than SMB when the analysis is divided into two different economic sub-periods. The forecasting results are better for HML than SMB when there's only one sector [4].

In addition, many scholars have tested the sensitivity of FF5F factors using exchange data and research on its correlation coefficients. Cox and Britten tested the effectiveness of the Fama-French five-factor model in explaining returns on the Johannesburg Securities Exchange(JSE). The research compared the traditional Fama-French three-factor model along with other factor combinations with Fama-French five-factor model. The results show that the five-factor model performs as well as the three-factor model in explaining the cross-section of returns on portfolios sorted by various characteristics. In addition, the model captures profitability and investment premia. The researchers point out that additional factors of profitability and investment help explain the return of JSE, among which profitability is better [5]. Also, Horváth and Wang evaluated the performance of Fama-French models on US stock markets during the financial crisis of 2008 and the covid-19 pandemic outbreak event by studying the $\mathrm{R}^{2}$ of the models. The researchers found that the influence of the Dotcom bubble on the $\mathrm{R}^{2}$ of the growth model is statistically significant. Both $\mathrm{R}^{2}$ of growth portfolios have a rapid decrement during the financial crisis of 2008 and the covid-19 outbreak. In addition, the study shows that all of the beta model parameters are insignificant in the GMM regression despite only market risk-free rate and the profitability matters to
OLS [6]. While Chen and Ho's research find evidence on mispricing and the five-factor model under different market sentiments. They used monthly value-weighted returns of the stock portfolios spanning from July 1972 to June 2015. Researchers used factor redundancy tests to examine whether each factor holds unique information that other factors cannot explain. The study finds that the two-factor model only significantly outperforms the five-factor model during the highsentiment periods. However, the two-factor model underperforms while the market sentiment is low [7].

The research of the above scholars fully proves that FF5F plays a very important role in studying the influencing factors of stock returns. Regarding the COVID-19 epidemic, some scholars also used FF5F to conduct research on the industries. $\mathrm{Yi}$ examined the performance of the Fama-French five-factor model in the US market before and after the Covid-19 outbreak. To verify the validity of the model during the pandemic, study whether there are unexplainable factors and whether the Fama-French factor beta changes due to the pandemic, the researcher applied the OLS method to 49 Fama-French industry combinations. The study finds that the efficiency of the Fama-French five-factor model has increased after the outbreak in all industries, while the unexplainable factor behaviour has increased. The pandemic has brought significant changes to FamaFrench factor betas in most industries and has strongly impacted portfolio performance and factor exposure [8]. Furthermore, With the help of the Fama-French fivefactor model, Hou and Chen analyzed the market changes in the US steel industry before and after the epidemic. The study used data from the Kennehr French-Data Library to conduct a multiple regression analysis of the US steel industry before and after the epidemic. The study concluded that due to the impact of COVID-19, the market risk factor (Betam) has decreased; the robustness reduction week (RMW) has changed from significant to insignificant. Small reduction of Big (SMB) and High reduction (HML) were significant, and the epidemic The change was not significant, and the Conservative minus Aggressive (CMA) was not significant. The conclusion is drawn that the epidemic's impact on the U.S. steel industry is huge, and it has led to a sharp decline in the entire industry [9].

In addition, the application scope of FF5F also includes investment forecasting, real estate, lodging industry, etc. Özkan studied the relationship between expected investment growth and stock returns in 20092018 in an emerging market. The research applied growth predictors, Fama-MacBeth regressions, portfolio analysis and Robustness check to investigate the predictive power of expected investment growth for stock returns. The study finds that expected investment growth predicts the future returns for portfolios on the long side. Also, the predictive power of the expected 
investment growth is greater for short time horizons [10]. Lee and Upneja aimed to compare the traditional method of estimating the cost of equity (the capital asset pricing model and the Fama and French three-factor model) with a new implied cost of equity method to provide accommodation analysts, investors, executives, and research Enrollment estimate with the cost of equity in a more reliable way. The study used data from the American City Lodging Company, range from 1976 to 2005, which provides all the necessary financial data for the cost of equity estimation. The study finds that, compared with CAPM and Fama-French five-factor model, the forward price benefit (PFE) method using the Implicit Cost of Equity (ICE) method is more reliable in estimating the cost of equity of publicly-traded accommodation companies of the lodging industry [11]. $\mathrm{Su}$ and Taltavull aimed to analyze the risk and excess returns of the Spanish real estate investment trusts(SREITS) by mainly applying the Fama-French threefactor model. The survey results show that the FF3 model is suitable for the S-EITs market. It explains the changes in S-return better than the traditional singleindex capital asset pricing model (CAPM) and the Carhart four-factor model. The revised FF3-type empirical results, which also include Spain's GDP growth rate, two consumer price index (CPI) macro factors and three dummy variables, indicate that GDP growth rate and CPI also affect $\mathrm{S}$ - The rate of return of REITS. At the same time, investment funds with capital requirements have less impact on the return of S-REITS [12].

\section{METHOD}

\subsection{Capital Asset Pricing Model}

The Capital Asset Pricing Model proposed by Treynor et al. is an equilibrium relationship between risk and the necessary rate of return in the case of sufficient combination.

$E\left[r_{i}\right]=r_{f}+\beta *\left(E\left[r_{i}\right]-r_{f}\right)$

(1)

$\beta=\frac{\operatorname{Cov}(r i, r m)}{\operatorname{Var}(r m)}$

(2)

Among them, the beta coefficient measures the systemic risk of a particular asset relative to the market portfolio. $r_{i}$ is the necessary rate of return of the $i$-th asset, $r_{f}$ is the risk-free rate of return (usually represented by the rate of return of Treasury bills), and $r_{m}$ is the necessary rate of return of average stocks (that is, the necessary rate of return of the portfolio when $\beta=1$ ).

\subsection{Fama-French Three-Factor Model Theory}

Fama and French increased the CAPM model from a single variable to three variables, namely the risk premium factor, the scale effect (SMB) and the value effect (HML), and improved the CAPM model to obtain the Fama-French three-factor model (FF3F) in 1993, and its basic form is as follows:

$E\left(R_{i}\right)-R_{f}=\beta_{i} E\left(R_{m}-R_{f}\right)+\gamma_{i} E(S M B)+\delta_{i} E(H M L)+\varepsilon_{i}$

Among them, $E\left(R_{i}\right)$ represents the actual investment portfolio return rate, $R_{f}$ represents the risk-free return rate, $E\left(R_{m}-R_{f}\right)$ represents the market risk portfolio return rate, $\mathrm{E}(\mathrm{SMB})$ represents the market value factor return rate, $\mathrm{E}(\mathrm{HML})$ represents the book-to-market value ratio factor return rate, $\beta_{\mathrm{i}}$ represents the stock market risk factor, $\gamma_{i}$ represents the market value factor coefficient, $\delta_{\mathrm{i}}$ represents the book-to-market value ratio factor coefficient, and $\varepsilon_{\mathrm{i}}$ represents the residual item.

\subsection{Fama-French Five-Factor Model Theory}

In 2015, Fama and French further proposed Famafrench five-factor model (FF5F), adding the profitability factor (RMW) and investment style factor (CMA) to the FF3F to better measure the return rate of the investment portfolio. The basic expression of the model is as follows:

$E\left(R_{i}\right)-R_{f}=\beta_{1} E\left(R_{m}-R_{f}\right)+\beta_{2} E(S M B)+\beta_{3} E(H M L)+\beta_{4}$ $E(R M W)+\beta_{5} E(C M A)+\varepsilon_{i}$

Where factor RMW (Robust Minus Weak) measures the difference between the high profit rate and the low profit rate of the stock portfolio, reflecting the premium of the high-profit stock investment relative to the lowprofit one. Factor CMA (Conservative Minus Aggressive) measures the difference between a conservative investment style and a radical investment style of stock portfolio returns, reflecting the high investment ratio model compared to the low investment ratio model.

\section{RESULTS}

The data is selected from the ken.french/data_library website. The study intercepted part of the original data. It divided it into two periods of 2019.5-2020.2 and 2020.3-2020.12, representing the pre-epidemic and post-epidemic stages (represented by before and after in the table below), respectively. This study selected 4 typical consumer goods industries, namely food, soda, beer and smoke. After the data was initially cleaned, it was derived by multiple linear regression (MLR). 
Table 1. 5-Factor regression of food industry

\begin{tabular}{ccccccc}
\hline \multirow{2}{*}{ Factor } & \multicolumn{3}{c}{ Before } & & After \\
\cline { 2 - 7 } Mkt-RF & Coefficients & t Stat & P-value & Coefficients & t Stat & P-value \\
SMB & 0.623 & 13.955 & 0.000 & 0.706 & 28.954 & 0.000 \\
HML & 0.187 & 2.226 & 0.027 & 0.342 & 5.390 & 0.000 \\
RMW & -0.108 & -1.259 & 0.209 & -0.010 & -0.187 & 0.852 \\
CMA & -0.127 & -0.905 & 0.366 & -0.256 & -2.428 & 0.016 \\
\hline
\end{tabular}

Table 2. 5-Factor regression of soda industry

\begin{tabular}{ccccccc}
\hline \multirow{2}{*}{ Factor } & \multicolumn{3}{c}{ Before } & & After & \\
\cline { 2 - 7 } Mkt-RF & Coefficients & t Stat & P-value & Coefficients & t Stat & P-value \\
SMB & 0.871 & 8.340 & 0.000 & 0.973 & 17.547 & 0.000 \\
HML & 0.417 & 2.121 & 0.035 & 0.298 & 2.066 & 0.040 \\
RMW & -0.076 & -0.379 & 0.705 & 0.110 & 0.927 & 0.355 \\
CMA & 0.439 & 1.338 & 0.182 & -0.581 & -2.426 & 0.016 \\
\hline
\end{tabular}

Table 3. 5-Factor regression of beer industry

\begin{tabular}{|c|c|c|c|c|c|c|}
\hline \multirow{2}{*}{ Factor } & \multicolumn{3}{|c|}{ Before } & \multicolumn{3}{|c|}{ After } \\
\hline & Coefficients & t Stat & P-value & Coefficients & t Stat & P-value \\
\hline Mkt-RF & 0.771 & 6.529 & 0.000 & 0.626 & 16.401 & 0.000 \\
\hline SMB & 0.082 & 0.371 & 0.711 & 0.260 & 2.615 & 0.010 \\
\hline HML & 0.189 & 0.828 & 0.409 & 0.065 & 0.800 & 0.424 \\
\hline RMW & -0.049 & -0.132 & 0.895 & 0.055 & 0.333 & 0.739 \\
\hline CMA & -0.390 & -0.888 & 0.376 & 0.183 & 0.861 & 0.390 \\
\hline
\end{tabular}

Table 4. 5-Factor regression of smoke industry

\begin{tabular}{|c|c|c|c|c|c|c|}
\hline \multirow{2}{*}{ Factor } & \multicolumn{3}{|c|}{ Before } & \multicolumn{3}{|c|}{ After } \\
\hline & Coefficients & t Stat & P-value & Coefficients & t Stat & P-value \\
\hline Mkt-RF & 0.584 & 4.582 & 0.000 & 0.798 & 16.160 & 0.000 \\
\hline SMB & -0.045 & -0.188 & 0.851 & 0.116 & 0.902 & 0.368 \\
\hline HML & -0.331 & -1.345 & 0.180 & 0.245 & 2.328 & 0.021 \\
\hline RMW & 0.038 & 0.095 & 0.925 & -0.447 & -2.093 & 0.038 \\
\hline CMA & 0.429 & 0.904 & 0.367 & 0.740 & 2.698 & 0.008 \\
\hline
\end{tabular}

As shown in Table 1-4, it can be concluded that the correlation coefficient of Mkt-Rf for each industry before and after the epidemic is significant and less than 1 , indicating that the consumer goods industry is less volatile than the market.

In addition, in the beer and smoke industries before the epidemic, except for the obvious linear relationship between Mkt-Rf and Ri, none of the other four factors have a significant linear relationship with $\mathrm{Ri}$.

Third, the significance of RMW before and after the epidemic has changed in almost all industries shown above (except the beer industry). The RMW of the food, soda, and smoke industries before the epidemic was not significant, and the change was significant after the epidemic. Among them, the absolute value of the Tvalue of RMW in the food and soda industries has become 2.4 after the epidemic, and the T-value of the RMW in the smoke industry is less significant, with an absolute value of about 2. Indicate that after the outbreak of the COVID-19, the high-profit rate of the stock is lower than the low-profit rate of the stock in these industries.

Fourth, the SMB factor of the beer industry has changed significantly before and after the epidemic. The SMB factor was not significant before the epidemic.
Still, it became significant after the epidemic, indicating that the size premium of the beer industry is positive after the outbreak of the COVID-19.

Furthermore, the significance of multiple factors in the smoke industry has changed before and after the epidemic. The three factors, HML, RMW, and CMA, were not significant before the epidemic and became significant after the epidemic, indicating that the value premium, profitability factor and investment style factor become related with $\mathrm{Ri}$.

\section{DISCUSSION}

Due to the global outbreak of the COVID-19 epidemic, the U.S. stock market has been severely affected, and many other countries have also been influenced. As a result, many consumer goods industries have been influenced. The above results show that the industry stock situation before and after the epidemic has undergone significant changes. The purpose of this study is to find out the changes and trends of the consumer goods industry stock market before and after the epidemic and find a reasonable explanation for this. 


\subsection{The whole consumer goods industry}

The consumer goods industry has strong demand rigidity. Therefore, the FF5F model simulations of all four industries before the epidemic show that their stock returns are only related to market risks. The other factors are not significant, indicating that stock returns are most affected by market systemic risks. In addition, it is worth noting that the coefficients of all MKT-RFs are less than 1, which means that the stock returns of the consumer goods industry are less volatile than the market. This also justifies the premise that the consumer goods industry has strong demand rigidity.

\subsection{Food industry}

The significance of the five factors in the food industry has not changed much before and after the epidemic. The results show only that the RMW and the stock return rate show a negative relationship after the epidemic. The coefficient of RMW is negative after the epidemic, which shows that low-profit companies in the industry have higher stock yields than high-profit companies. Combined with the overall social background, the epidemic has brought about home isolation and increased unemployment, which directly led to a decline in people's income. Therefore, the companies with low profitability also have a chance to achieve better financial performance. Therefore, the increase in the yield of companies with lower gross profit margins is higher than that of companies with higher gross profit margins. However, the food industry is demanded rigid after all. Therefore, the absolute value of the coefficient of RMW is also low (the absolute value is only 0.256 , as shown in Table 1 ).

\subsection{Soda industry}

The regression results of the FF5F model of the soda industry are similar to those of the food industry, and the relationship between RMW and stock returns has become significant after the epidemic. The coefficient of RMW after the epidemic is also negative, indicating that the contribution of low-profitability companies to the rate of return is better than that of high-profitability companies. On the one hand, people's income levels have fallen due to the epidemic, which gives the lowprofitability corporations chances; on the other hand, the raw materials of soda water are sodium bicarbonate $\left(\mathrm{NaHCO}_{3}\right)$, potassium chloride $(\mathrm{KCl})$, citric acid, etc. The prices of these chemical products have been inverted after the epidemic. Lower prices of upstream products have also brought about changes in the impact of profitability on return rate.

\subsection{Beer industry}

The change in the coefficient of the five factors in the beer industry is that the impact of SMB on Ri after the epidemic has become significant and positively correlated. This means that company size is negatively correlated with excess returns. That is, companies with low net worth tend to have higher returns. The epidemic has pushed the global economy down, and small-scale companies are more sensitive to changes in market risk. Thus, risk compensation has also appeared and give small-scale companies opportunities for thriving.

\subsection{Smoke industry}

As shown in Table 4, the smoke industry has undergone major changes before and after the epidemic. RMW became significant and negatively correlated with $\mathrm{Ri}$ for the same reasons as the food and soda industries. HML becomes significant and positively correlated with $\mathrm{Ri}$, indicating that book value has a greater impact on $\mathrm{Ri}$ than market value. The increase in leisure time brought about by home quarantine and the popularity of ecigarettes has caused the smoke industry to show an upward trend after the epidemic. Therefore, it has brought about an increase in the impact of the book value of the smoke industry on the rate of return. CMA has become significant after the epidemic and is positively correlated with $\mathrm{Ri}$, indicating that the investment style in the smoke industry has become conservative, further revealing that the pattern of the smoke industry is relatively stable.

\section{CONCLUSION}

The study uses the Fama-French five-factor (FF5F) model to explore the impact of COVID-19 on the consumer goods industry group in the US stock market. The study uses multiple linear regression (MLR) to calculate the data and obtain the five factors' significance and coefficient changes before and after the epidemic. According to the research, for different industries, some factors of Mkt-Rf, SMB, HML, RMW, and CMA have changed before and after the epidemic. As for the entire consumer product industry group, RMW has changed the most before and after the epidemic, with changes in all three industries. This change shows that people have become more speculative in the U.S. stock market after the epidemic. The significance of this research is to provide a reference for research on the impact of COVID-19 on other industry groups in the stock market and the economic influence of major health events in the future.

\section{REFERENCES}

[1] Yasir Wahab.(2017).Testing Short Term and Long Term Applicability of CAPM: A Case of Pakistani 
Cement Industry. Research Journal of Finance and Accounting(7)

[2] Eugene F. Fama \& Kenneth R. French. (2015). A five-factor asset pricing model. Journal of Financial Economics doi:10.1016/j.jfineco.2014.10.010.

[3] Eugene F. Fama \& Kenneth R. French. (2017). International tests of a five-factor asset pricing model. Journal of Financial Economics (3), doi:10.1016/j.jfineco.2016.11.004

[4] Melih Madanoglu,,Michael D. Olsen \& Francis A. Kwansa. (2005). Empirical Investigation of the CAPM vs. Fama-French Model: Evidence from the Lodging Industry. The Journal of Hospitality Financial Management doi:10.1080/10913211.2005.10653809.

[5] Marcelo Gonçalves \& Andre Carvalhal. (2017). Predicting Fama-French factors based on industry returns in Brazil. Corporate Ownership \& Control (1), doi:10.22495/cocv15i1art4.

[6] Shaun Cox \& James Britten. (2019). The FamaFrench five-factor model: Evidence from the Johannesburg Stock Exchange. Investment Analysts Journal doi:10.1080/10293523.2019.1647982.

[7] Horváth Dominik \& Wang Yung Lin. (2020). The examination of Fama-French Model during the Covid-19. Finance Research Letters (prepublish), doi:10.1016/J.FRL.2020.101848.

[8] En-Te Chen \& Jerry C. Ho. (2020). Mispricing and the five-factor model under different market sentiments. Heliyon doi:10.1016/j.heliyon.2020.e04191.

[9] Yi Sun. (2020). Analysis of Fore and Aft Covid-19 Impact on Industry Data Based on Fama-French Five Factors. (eds.) 2021 International Conference on Electronic Commerce, Engineering Management and Information Systems(pp.). Francis Academic Press.

[10] Hou Dingwen \& Chen Zirui. (2021). Research on the application of Fama-French 5-factor model in the steel industry during COVID-19. Journal of Physics: Conference Series (4), doi:10.1088/17426596/1865/4/042104.

[11] Özkan Nesrin. (2021). Expected investment growth and stock returns in an emerging market. Economics Letters (prepublish), doi:10.1016/J.ECONLET.2021.110008.

[12] Seoki Lee \& Arun Upneja. (2008). Is Capital Asset Pricing Model (CAPM) the best way to estimate cost-of-equity for the lodging industry? International Journal of Contemporary Hospitality Management doi:10.1108/09596110810852159.

[13] Zhenyu Su \& Paloma Taltavull. (2021). Applying the Fama and French three-factor model to analyze risk/reward in the Spanish REITs: an ARDL approach. Journal of European Real Estate Research (2), doi:10.1108/JERER-11-2019-0043. 